\title{
Slouching Toward A Systems Approach to Treatment
}

\author{
FREDERICK B. GLASER* \\ University of Michigan Substance Abuse Center, Ann Arbor, MI
}

\begin{abstract}
GLASER, F. B. Slouching toward a systems approach to treatment. ALCOHOL 11(6) 467-470, 1994. - Both the health care sector generally and the alcohol and drug field are moving toward a truly systematic approach to treatment, accelerated by the anticipated advent of health care reform. There is considerable reluctance to develop systems. Many are not convinced of their necessity, and systematization inevitably involves a decrement in autonomy for the components of the system. Nor are systems panaceas; they have problems of their own, such as the bottleneck. But only true systems will be able to cope with the expected increase in demand for services that will accompany the universal entitlement of health care reform. Recent work giving the alcohol and drug treatment field an edge in systems development is discussed. Regrettably, the main motivation for deploying systems has become economic. They would more appropriately be justified by their potential for enhancing the efficacy of treatment.
\end{abstract}

Systems Treatment systems Alcohol treatment Drug treatment Health care reform Resistance to systems development

The last temptation is the greatest treason: To do the right deed for the wrong reason.

$$
\text { -T.S. Eliot, Murder in the Cathedral (5) }
$$

WHAT IS A SYSTEM?

Because in everyday speech we are accustomed to speak of "the treatment system," some explanation of what is meant by the phrase "a systems approach to treatment" may not be amiss. What is referred to as "the treatment system" is commonly the aggregate of all of the persons, facilities and programs that provide treatment, in this instance treatment for alcohol and drug problems. In fact, however, a system - a "true" system, if you will-is much more than the aggregate of its individual elements.

The essence of a system has to do with the connections between its basic elements. For a system to exist, the dictionary tells us, its component parts must be "connected, associated, or interdependent, so as to form a complex unity; a whole composed of parts in orderly arrangement according to some scheme or plan" (13). Because of these connections flow can occur within the system, and it is to facilitate flow that the system exists. A very simple example is a plumbing system. Faucets, sinks, drains, traps, pumps, wells, and reservoirs do not by themselves comprise a plumbing system. It is not until these elements are joined together by a network of sluice ways, aqueducts, pipes, and other connectors that water can flow through the system.

Another illustrative example of the development of a sys- tem is the history of the computer chip. The first step toward the miniaturization of complex electrical systems was the invention of the transistor as a replacement for the vacuum tube. But although the transistor was highly satisfactory in terms of its functional capabilities and its small size, a serious practical problem was encountered in its deployment. It was so small that soldering workable connections between it and other elements of the system was a very difficult feat. Companies that manufactured transistorized equipment began to employ women exclusively to assemble these products, believing that their small and delicate hands would be able to cope with these difficulties. Unfortunately, a high proportion of products continued to have dysfunctional circuitry. Ultimately the problem was solved by developing a new device in which the critical elements necessary to modulate electronic flow were present, but in which the connections between these elements were also prespecified and were produced at the same time as the elements as part of an integrated unit. This unit was the computer chip (14).

In medicine, we are familiar with systems in at least two ways. First, we study various systems within the body: the nervous system, the endocrine system, the circulatory system, the immune system, and so forth. Clearly, the connections between parts and issues of flow are of the essence in these systems. Moreover, they are highly complex, with multiple feedback and control mechanisms that we are only beginning to understand. But at least at this level, we have an appreciation of systems and their functions.

*Current address: Walter B. Jones Alcohol and Drug Treatment Center, 2577 West Fifth Street, Greenville, NC 27834. 
At another level, those who are involved in medical practice are aware - sometimes dimly, sometimes acutely - of developments in health care delivery that have to do with systematization. Their touchstones are terms like "managed care" and "health maintenance organizations." Although these kinds of systems are formally similar to the anatomical and physiological systems we are more familiar with, we have much further to go to develop an appreciation of them. And beyond them stands the specter of national health care systems, particularly of the Canadian system, which is poorly understood on this side of the border ( $c f$. 4) and, perhaps because of this, regarded with much fear and suspicion.

Nevertheless, it is indisputable that we are moving toward the widespread development of systems of health care. In medicine generally, this evolution goes under the rubric of "health care reform." Although the initiatives now being championed by the Clinton administration are not presented as leading to true systems of care, that is what they are fundamentally about. At this writing it appears that treatment for alcohol and drug problems will be included in these initiatives, and so this field as well as that of medicine generally is beginning to recognize what is likely to be the shape of things to come.

\section{RESISTANCE TO SYSTEMS}

The title of this article is meant to indicate both that we are moving toward a true system of service delivery and that we are doing so with reluctance. It is a paraphrase of some lines from a well-known poem of W. B. Yeats entitled The Second Coming (17). The poem depicts a chaotic situation ("The falcon cannot hear the falconer;/Things fall apart; the centre cannot hold;/ Mere anarchy is loosed upon the world"). "Surely," the poet says, "some revelation is at hand." That revelation will resolve the situation; and yet he indicates that the notion "troubles my sight," because he is fearful of what form the revelation will take: "And what rough beast, its hour come round at last,/Slouches toward Bethlehem to be born?"

The reluctance to look toward a systems approach as an answer to problems in service delivery arises for a number of reasons. One is the concern that forcing them prematurely into being to meet the demands of a chaotic present may give rise to maladaptive systems, as is implied by Yeats. Another reason for reluctance is the continuing suspicion that the development of systems of care is not really necessary.

The usual form taken by this argument is that medical science will develop relatively straightforward, simple, technological innovations that will automatically take care of matters such as alcohol and drug problems (cf. 6). No particular effort is required to assure that such technology will be utilized; if it is shown to be effective, it will be used. One could label this the "trickle-down" theory of health services delivery. As in the economic theory of the same name, benefits at one level would automatically produce benefits at other levels.

A high-ranking federal official once encouraged me to accept these ideas by using the example of tuberculosis. He noted that, not so many years ago, patients with one form or another of tubercular infection were the most common inhabitants of medical wards. Now, he indicated, they are rarely seen. He insisted that the reason for this positive change was the development of effective chemotherapeutic agents. Their deployment did not require radical changes in health care delivery. Once their efficacy had been demonstrated, physicians in the course of their practice began to use them, and that took care of the problem. The same thing would happen, he said, when an agent that was effective in eliminating craving for alcohol and drugs was developed, a breakthrough that he assured me was imminent. Thus, all available resources should be diverted to the development of such agents, and the rest would take care of itself.

With all due respect, there are some difficulties with this argument. First, tuberculosis, like some other infectious diseases, has a necessary cause-the tubercle bacillus. As those of us who are tuberculin positive will testify, the bacillus is not sufficient by itself to cause clinical illness. But it must be present for the illness to develop. Strategically, then, the necessity of the bacillus allows a straightforward approach to management: neutralize or eliminate its presence, and you prevent or cure the illness.

However, alcohol and drug problems, unlike tuberculosis, do not have any necessary cause. They can arise for a variety of different reasons in different individuals (10). Such problems are also highly heterogeneous. While some individuals do indicate they have cravings for their substances of choice that are difficult to deal with, others do not; craving is by no means a universal phenomenon in such problems. Therefore the analogy with tuberculosis is strained.

Second, the argument overlooks the fact that, in common with many other infectious diseases, there has been a marked decline in the prevalence of tuberculosis that long antedates the development of specific medication. The earliest comprehensive records derive from English parish registries, beginning in approximately the 1830 s, and show a steady and regular decline from that time forward. The factors thought to be responsible are such general ones as the development of a safe water supply and the provision of a fully adequate diet for the population as a whole, the result historically of the introduction and cultivation of the lowly potato. There is no doubt that the introduction of effective chemotherapy was an unqualified good and did result in an acceleration of the decline in mortality; but that decline had already been under way for more than a century (11).

Third, tuberculosis has not in fact disappeared. There is now a resurgence of infections in some of the less privileged sectors of society. I conclude, therefore, that the analogy of tuberculosis is not apt. Even if it were apt, it is not encouraging, since we continue to have problems with tuberculosis. This is by no means to say that the development of effective medications is not an important matter in our struggle to deal effectively with alcohol and drug problems. It is an essential endeavor and is to be strongly encouraged as an important part of a multipronged strategy of attack. And it is a very exciting and promising area, as the presentations of O'Brien, Myers, and Smith to this conference so effectively indicate.

But we should not feel that drug development - or indeed the development of any single area relevant to therapeutics, including service delivery - is likely to provide the key to effective treatment in and of itself. I think back to O'Brien's conclusion that the narcotic antagonists, when applied to alcohol problems, are not effective for a majority of individuals, and that they tend to be of maximum value as part of an overall therapeutic approach that includes other elements such as psychotherapy. A recent and very important publication from his group has indicated that the same is true for methadone in the treatment of opiate problems (12). I think as well of the multisite trial of disulfiram (Antabuse), which demonstrated conclusively that it was not effective in and of itself (7).

Ironically, disulfiram and methadone were specific items in Etzioni and Remp's (6) explication of simple technological answers to complex social problems. It seems, rather, that 
complex problems, like alcohol and drug problems, require complex solutions. We should be importantly hindered in our attempts to cope with such problems absent an influx of effective therapeutic agents. But on the other hand we should not be sapient strategists if we limited our armamentarium to weaponry of only one type.

Thus, there should be no reluctance to use systems approaches to the treatment of major problems on the grounds that they are not necessary. Quite the opposite is the case; the principal justification for using a systems approach is to enable us to cope with complex problems that are highly prevalent. According to the Epidemiologic Catchment Area (ECA) study, a population-based epidemiologic survey that contains the best information on this score, severe problems with alcohol are "one of the most common lifetime psychiatric disorders in America" $(9$, p. 113). Past studies $(2,15)$ had indicated that only a small proportion of persons with severe alcohol problems have ever received formal treatment for them. This was confirmed in the ECA study, in which only $12 \%$ of those with a diagnosis of alcoholism had ever talked to a doctor about it (9, p. 109). Thus, a substantial proportion of such persons remain unserved. As one of the principal initiatives of health care reform is to make treatment available to everyone, it seems likely that many more persons with alcohol (and drug) problems will seek treatment. It seems unlikely that anything other than a carefully planned service delivery system will be able to cope with the ensuing demand. A system of treatment, at least in this area, does seem to be a necessity.

Are there further grounds for reluctance to set up a system of treatment? At least two other objections come to mind. One involves the reduction in autonomy that is a necessary concomitant of becoming a component of a system. For the components to fit together into an integrated whole with a minimum of redundancy, each component must content itself with its assigned role. Since in their previous incarnations the components had stood alone, they commonly have subserved multiple functions. Entering a system necessarily involves surrendering some of those functions, as well as depending upon others to perform them.

But surrendering even an iota of autonomy is an unpleasant prospect. There is something almost un-American about it (cf. 16). It also involves an element of trust in whatever or whomever is responsible for the design and maintenance of the system. Such trust has not commonly been in abundance in the therapeutic arena, which (especially in the U.S.) has more often been characterized by competition rather than interdependence.

Finally, while systems can realistically hold out the possibility of producing great benefits, there is more often a balance between positive and negative effects. Systems are not miraculous nor immune to problems. Indeed, when a system develops a problem, it is often of great magnitude. If the salient feature of a system is flow, the classic systems problem is the reduction or blockage of flow - the so-called bottleneck. Anyone who has suffered through a traffic backup of many miles on the interstate highway system understands this problem very well. Yet who would wish to forego the convenience and safety of the highway system because it is not entirely problem-free?

In sum, there are several sources of reluctance regarding the establishment of treatment systems, some more reasonable than others. The bottom line, however, is that there is no reasonable alternative to the development of treatment systems if we are to provide health care services to all those who need them. Only a system can cope with demands of this kind; demands which, with the advent of health care reform, may be expected to increase markedly in future. Some would argue that providing this level of service is not simply a political necessity but is a moral necessity as well (8).

\section{RECENT DEVELOPMENTS}

Fortunately, there have been developments in the substance abuse area that indicate it is preparing actively for this necessity. While these developments have their roots in the past, only some of the more recent will be mentioned here. In 1990, the Institute of Medicine (IOM) of the National Academy of Sciences issued a report entitled Broadening the Base of Treatment for Alcohol Problems (10). The result of a lengthy study by an expert committee, the report envisioned a systems approach to treatment that it outlined in considerable detail in its more than 600 pages, but perhaps most succinctly in chapters 1 and 13.

Several important initiatives have been undertaken that already have or soon will provide independently much needed detailed information on aspects of the system envisioned in the IOM report, as well as on systems as a whole. The World Health Organization has completed a multisite, multinational trial of particular methods of identifying alcohol problems and utilizing brief interventions to deal with them in primary care settings (1). This landmark study joins a host of others that have explored and confirmed the efficacy of brief interventions [reviewed in (3)]. The approach taken in these studies is highly consonant with the community role in treatment discussed in chapter 9 of the IOM report (10).

Another important initiative in the United States has been Project MATCH (an acronym for Matching Alcohol Treatment to Client Heterogeneity), as discussed by Dr. Frances Del Boca in this symposium. Once again we have a multisite study, this time within the United States. A group of investigators has looked carefully at guidelines that might predict which persons with alcohol problems will achieve the best outcomes from which of three specific and different treatment approaches. Matching of this kind was viewed as central to its treatment system plan by the IOM Committee (see especially chapter 11). Although the results of Project MATCH are not yet available, the recruitment and treatment of some 1700 individuals has already been completed. Such an undertaking can only be of the most particular help in shaping and informing future approaches to treatment.

Finally, the Center for Substance Abuse Treatment in the federal government has undertaken a major field demonstration of treatment systems in the substance abuse area. Nineteen cities are now participating in what is called the Target Cities project (Albuquerque, Atlanta, Baltimore, Boston, Chicago, Cleveland, Dallas, Detroit, Los Angeles, Miami, Milwaukee, New Orleans, New York, Newark, Philadelphia, Portland, Saint Louis, San Francisco, and San Juan). The treatment systems are required to possess such features as a central intake, matching of clients to multiple different treatments, computerized management information systems, evaluation of outcome, and others. These are elements viewed as important in the IOM report and also in other reports on treatment systems. A remarkable undertaking of unusual scope and vision, the Target Cities project cannot fail to provide invaluable guidance for the future development of systems in the substance abuse area and in other areas as well.

\section{THE RIGHT DEED FOR THE WRONG REASON}

Developments such as these can only be extremely gratifying to those who are committed to systems as a necessary part 
of the exercise of the universal right to health care. But there is, regrettably, a less positive side to recent developments as well. It is reflected in the epigraph to this paper, taken from T. S. Eliot's verse drama, Murder in the Cathedral (5).

The story of the play is familiar and deals with Thomas Becket (1118-1170), formerly chancellor of the realm, longtime friend of King Henry II of England, and recently (1162) appointed by the king to be Archbishop of Canterbury. From the beginning of his tenure as Archbishop, Becket was wholly captured by the role and in time became the king's most implacable foe. In the play, Becket is challenged by four Tempters, who urge him to differing courses of action. The final and greatest temptation is to persist in his opposition not because it is the right course of action, but because it will inevitably end in martyrdom that will (through subsequent sainthood) assure his immortality. This is what is meant in the context of the drama by doing the right deed for the wrong reason: opposing the King not because he is wrong, but for personal gain.

With regard to systems of treatment, we seem also to be doing the right thing for the wrong reason. We are in the process of implementing systems approaches, and that is (in my view) the right deed. But we are doing so primarily because this is the least expensive way to provide needed services to all, and that is (in my view) the wrong reason. By having delayed the implementation of treatment systems to this point in time, we have allowed ourselves to be forced into them for economic reasons. When President Clinton speaks about the necessity for health care reform, his principal argument invariably is that it is essential for the American economy; in our rather smaller area of alcohol and drug problems, there are limited resources available and a cost-saving approach such as systems development is necessary for the same reason.

Thank heaven for small favors, to be sure. At least it looks as if the systems approach to treatment may finally receive a reasonable trial. But my sense of satisfaction at this outcome is tempered by the knowledge that this could have been done primarily because treatment systems hold out the promise of the most effective care, rather than the least costly care. Care can of course be both effective and of reasonable cost - it can be cost effective-and that is the great hope. But how much more satisfying it would have been had we willingly developed systems approaches to treatment because they work, rather than being dragged into them kicking and screaming because we lack funds. Hopefully, the next time major health care innovations are required, we will do the right thing for the right reason.

\section{REFERENCES}

1. Babor, T. F.; Grant, M., eds. Project on identification and management of alcohol-related problems. Report on Phase II: A randomized clinical trial of brief interventions in primary health care. Document WHO/PSA/91.5. Geneva, Switzerland: Programme on Substance Abuse, World Health Organization; 1991.

2. Baekeland, F.; Lundwall, L. K. Engaging the alcoholic in treatment and keeping him there. In: Kissin, B.; Begleiter, H., eds. The biology of alcoholism, vol. 5. Treatment and rehabilitation. New York: Plenum Press; 1977:161-195.

3. Bien, T. H.; Miller, W. R.; Tonigan, J. S. Brief intervention for alcohol problems: A review. Br. J. Addiction 88:315-336; 1993

4. Detsky, A. S. Northern exposure-Can the United States learn from Canada? New Engl. J. Med. 328:805-807; 1993.

5. Eliot, T. S. Murder in the Cathedral: The centennial edition. San Diego: Harcourt Brace Jovanovich; n.d.

6. Etzioni, A.; Remp, R. Technological "shortcuts" to social change. Science 175:31-38; 1972.

7. Fuller, R. K.; Branchey, L.; Brightwell, D. R.; Derman, R.M.; et al. Disulfiram treatment of alcoholism: A Veterans Administration cooperative study. JAMA 256:1449-1455; 1986.

8. Glaser, F. B. A matter of moral perspective. Br. J. Addiction 86: $18-19 ; 1991$

9. Helzer, J. E.; Burnham, A; McEvoy, L. T. Alcohol 'se and dependence. In: Robins, L. N.; Regier, D. A., eds. Psychiatric disorders in America: The Epidemiologic Catchment Area study. New York: The Free Press; 1991:81-115.

10. Institute of Medicine. Broadening the base of treatment for alcohol problems. Washington, DC: National Academy Press; 1990.

11. McKeown, $T$. The modern rise of population. London: Edward Arnold; 1976:92-93.

12. McLellan, A. T.; Arndt, I. O.; Metzger, D. S.; Woody, G.E.; O'Brien, C. P. The effects of psychosocial services in substance abuse treatment. JAMA 269:1953-1959; 1993.

13. Murray, J. A. H.; Bradley, H.; Craigie, W. A.; Onions, C. T., eds. The Oxford English dictionary. Oxford: The Clarendon Press; 1933.

14. Reid, T. R. The chip: How two Americans invented the microchip and launched a revolution. New York: Simon and Schuster; 1984.

15. Smart, R. G.; Gillies, M.; Brown, G.; Blair, N. L. A survey of alcohol-related problems and their treatment. Can. J. Psychiat. 25:220-227; 1980.

16. Spitzer, W. O.; Starfield, B. Health services research can make a difference. New Engl. J. Med. 297:1406; 1977.

17. Yeats, W. B. The second coming. In: Finneran, R. J., ed. The collected works of W. B. Yeats. Volume 1: The poems. New York: Macmillan Publishing Company; 1990. 